\title{
Job satisfaction vs. organizational climate: cross- sectional study in brazilian nursing professionals
}

Ricardo Toshio Yamassake

Universidade de São Paulo

Patricia Campos Pavan Baptista

Universidade de São Paulo

Vinicius Anselmo Albuquerque

Universidade de São Paulo

Chennyfer Dobbins Abi Rached ( $\nabla$ chennyfer@usp.br)

Universidade de São Paulo

\section{Research Article}

Keywords: job satisfaction, organizational climate, nursing professionals

Posted Date: July 1st, 2021

DOI: https://doi.org/10.21203/rs.3.rs-601567/v1

License: (c) (1) This work is licensed under a Creative Commons Attribution 4.0 International License. Read Full License 


\section{Abstract \\ Background}

The organizational climate is one of the relevant constructs in the field of organizational behavior, being a construct investigated over the years. Considering the concerns that permeate the health of nursing workers and, believing that the organizational climate can interfere with job satisfaction, the present study seeks to relate the job satisfaction of the nursing team and the organizational climate in a University Hospital.

\section{Methods}

cross-sectional, quantitative study. EQUATOR checklist used to report the study is SQUIRE 2.0. The sample consisted of 226 nursing workers from a university hospital on the west side of the city of São Paulo, Brazil. A Socio-demographic and Professional Characterization Questionnaire, Organizational Climate Scale for Health Organizations (ECOOS), and Work Satisfaction Questionnaire (S20 / S23) were been applied.

\section{Results}

There is no correlation between Organizational Climate and Job Satisfaction and the higher the Organizational Climate score, the higher the Work Satisfaction score. The relationship between job satisfaction and organizational climate is complex and is associated with each individual's experience and the way they interpret these experiences.

\section{Conclusion}

There is a correlation between job satisfaction and organizational climate; it was verified through the applied instruments that several dimensions and sub-dimensions are associated with this relationship. Leadership was one of the most prominent dimensions. Implications for Health Policy: understanding the relationship between organizational climate and job satisfaction provides subsidies for the elaboration of strategies to mitigate the processes of exhaustion, illness, and incapacity of workers, as well as helping to improve the productivity and effectiveness of the nursing work process.

\section{Background}

The influence of work in the life of the human being is undeniable because, through it, he establishes his dignity, obtains sustenance, social status and promotes relationships ${ }^{1}$. It is limited to work, depending on 
the way in which it is organized, the enhancement of wear and/or strengthening factors in the healthdisease process ${ }^{2}$.

The work context experienced by nursing workers, characterized by inadequate resources, both in quantitative and qualitative aspects, in addition to technological incorporation, increased complexity of processes and demands for high productivity and goals, are elements that have caused aggravations to health of this group ${ }^{3}$.

On the other hand, it is also important to highlight that the work process carries with it positive elements, which are related to satisfaction and well-being, which must be investigated. Research on organizational climate has been carried out in order to understand how workers behave in organizations, how they feel about the climate and its influence on well-being ${ }^{4}$.

The concept of organizational climate is the values attributed by the individual with regard to the practices and behaviors experienced in companies. In case sense that the climate has described as the shared perception of workers in the work environment ${ }^{5}$. A positive organizational climate can lead to less stressed and exhausted workers. At the same time, a stressful work environment can lead to less job satisfaction and therefore negatively influence employee well-being ${ }^{6,7}$.

The organizational climate portrays the perceptions of the set of individuals of a given organization about their work context. This involves the most diverse factors, such as relationship with peers and the boss, the tasks to perform, the benefits, working conditions, among others, which may be one of the vulnerability factors for the development of work stress conditions ${ }^{8}$. It is worth mentioning that this concept is broad and can be seem in different ways, which lead to inaccuracies and interpretations of divergent organizational culture ${ }^{9}$.

The organizational climate is one of the relevant constructs in the field of organizational behavior, being a construct investigated over the years. It is a theme related to the individual's perception of the work environment, constituting a regulatory and guiding tool for human behavior within organizations ${ }^{8}$. The organizational climate has also a theoretical scope of the construct and the ability to analyze characteristics such as interpersonal relationships, leadership, recognition, reward, among others, based on the perceptions of the organization's workers, which implies the perception of job satisfaction ${ }^{9}$.

The situations perceived by the nursing team brought to light the determinant of job satisfaction as a source of influence on well-being and safety in clinical practice, as well as changes in the context of the climate and the team's commitment to carrying out its activities ${ }^{10}$.

Considering the concerns that permeate the health of nursing workers and, believing that the organizational climate can interfere with job satisfaction, the present study seeks to relating the job satisfaction of the nursing team and the organizational climate in a University Hospital. 


\section{Methods}

\section{Design}

This is a cross-sectional field study with a quantitative approach. EQUATOR checklist used to report the study is SQUIRE 2.0.

\section{Sample and settings}

The research was carried out at the University Hospital of the University of São Paulo, located in the west of the city of Sao Paulo, in the state of Sao Paulo. The sample consists of 226 workers on the nursing team. The inclusion criteria were to be train in nursing, either at the level of higher or secondary education. Exclusion criteria were professionals who were on leave due to sick leave, pregnancy or vacations.

\section{Dependent variable}

The organizational climate and job satisfaction constructs have been considered respecting the global scores.

\section{Independent variables}

It will be considered the demographic characteristics (age, sex, marital status, number of people with whom you live, family income, education, professional training, leisure activities and care for dependents at home) and functional characteristics (personal income, workplace, position, length of professional experience, average number of weekly hours of work and other employment relationships).

\section{Data collection}

Data was collected in 2019. The Free and Informed Consent Form, as well as the questionnaires were been delivered personally to each study participant by the researchers. For the collection, the delivery date was been scheduled according to the availability of the workers and the researcher. Furthermore, it has been established that for situations of negligent participants with the delivery deadlines of the instruments, up to three new dates for the return were proposed without fail. Otherwise, it was been interpreted as data loss due to the participant's withdrawal. Three instruments were been used: Sociodemographic and Professional Characterization Questionnaire, Organizational Climate Scale for Health Organizations (ECOOS) and Work Satisfaction Questionnaire (S20 / S23).

ECOOS was developed and validated by Menezes et al. (2009) and consists of 64 items, assessed on a 5point scale ranging from "Strongly disagree" (1) to "Strongly agree" (5). It consists of seven dimensions: Leadership, Professional development, Relationship and team spirit, Relationship with the community, Safety at Work, Strategy and Compensation. To check job satisfaction, it was used the Job Satisfaction Questionnaire (S20/S23), prepared by Meliá and Peiró, Brazilian version of Carlotto and Câmara ${ }^{11}$ with 
20 items, evaluated on a 5-point scale ranging from "Totally dissatisfied"(1) to" Totally satisfied "(5). It consists of three dimensions: Satisfaction with Hierarchical Relations, Satisfaction with the Physical Work Environment and Intrinsic Satisfaction at Work.

\section{Ethical considerations}

This research project has approved by the Research Ethics Committee of the School of Nursing at the University of Sao Paulo, under opinion 912.483 of 11/17/2014 and formal authorization from the service that hosted the collection. The informed consent obtained from study participants was written, in accordance with the IRB rules.

\section{Data analysis}

Double data entry has done in a Microsoft Excel spreadsheet. Then, the files were exported to the STATA software version 14 to check the validity, consistency, correction and recoding of the data, with subsequent statistical analysis. Epi Info software version 3.5.4 from the Centers for Disease Control and Prevention has used to analyze the losses.

The reliability analysis of the questionnaires used was been carried out using Cronbach's alpha coefficient.

The characterization of the study population was been carried out through descriptive analysis using means, standard deviations, minimum and maximum values of the scores of the quantitative variables and proportions for the qualitative variables. As for the analysis of the associations between job satisfaction and organizational climate and job satisfaction, a bivariate analysis of the factors associated with job satisfaction was been performed with the Shapiro-Wilk test to verify the adherence of the Job Satisfaction score to the normal distribution, determining the types of statistical tests to be used.

The correlations between quantitative variables and the Job Satisfaction score were been analyzed using Pearson's correlation coefficient for variables with normal distribution and Spearman's correlation coefficient for nonparametric variables. To compare the means of the Job Satisfaction score according to the categories of qualitative variables, the homogeneity of variances was been initially assessed using the Barlett test. Since the variables presented constant variance, the ANOVA test used. With a statistically significant difference between the means, the Bonferroni post hoc test was been performed for multiple comparisons.

The regression analysis between Job Satisfaction and Organizational Climate was also been performed. Then, the remaining variables that presented $p<0.20$ in the bivariate analysis were inserted in the modeling. The " $p$ " value determined the order of entry into the multiple model. The modeling process was stepwise forward. The independent variable remained in the multiple model if $p<0.05$ and / or if it was an adjustment variable. Qualitative variables were been transformed into indicator variables (Dummy). In all analyzes performed, the significance level of $5 \%$ was used. 


\section{Results}

The sample consisted of 226 professionals from the nursing team, $88.5 \%(n=200)$ of whom were female; age range between 50 and 59 years $36.3 \%(n=82)$; as for professional training $54.4 \%(n=123)$ were nursing technicians; $36.3 \%(n=82)$ had 21 years or more of experience in the studied hospital, as can be seen in Table 1.

There was a statistically significant correlation between Organizational Climate and Job Satisfaction, the higher the Organizational Climate score, the higher the Job Satisfaction score $(p<0.001, r=0.424)$. The confirmatory analysis of the dimensions of each of the variables used was been performed using the structural equation model to test the relationships between the variables. The confirmatory analysis of Cronbach's alpha for the climate was 0.95 . The global score (considering all the questions in the questionnaire) presented a Cronbach's alpha coefficient of 0.95 . The exclusion of any question would not lead to an improvement in the results of the dimensions or the global score.

The Job Satisfaction variable, Cronbach's alpha, was 0.85 , except for the remuneration dimension, which obtained a result of 0.79 . The global score (considering all questions in the questionnaire) presented a Cronbach's alpha coefficient of 0.97 . The exclusion of any question would not lead to an improvement in the results of the dimensions or the global score.

The global score for Job Satisfaction had an average of 3.22 points (SD $=0.89$ points) and a median of 3.30 points, ranging from 1.20 to 5.00 points. As for the dimensions, the highest level of satisfaction was in Intrinsic Job Satisfaction (average of 3.30 points; SD $=1.03$ points) and the lowest level was in the Physical Work Environment (average of 3.13 points; $S D=1.08$ points). The average of Hierarchical Relations was 3.25 points (SD $=1.02$ points).

The Shapiro-Wilk test demonstrated that the Job Satisfaction score had a normal distribution $(p>0.05)$ and the other quantitative variables showed a non-parametric distribution $(p \geq 0.05)$. Among the correlations carried out, it was found that only age showed a statistically significant association with Job Satisfaction, and the higher the age, the higher the level of satisfaction $(p=0.029, r=0.0 .146)$.

The Table 2 presents dimensions of job satisfaction with emphasis on dimension 3 - Intrinsic Job Satisfaction and with higher scores on the opportunities that work offers to do things that you enjoy and work as a conduit for achievement, both with 3.37 points.

The correlation of functional characteristics with Job Satisfaction, only the job sector was associated with Job Satisfaction $(p=0.001)$, with the highest levels of satisfaction occurring in the sectors classified as "Outpatients" (average of 4.60 points). Clinical nursing showed the highest level of satisfaction (average of 3.55 points, $S D=0.87$ ) and pediatric nursing brought the lowest level of satisfaction (average of 2.88 points, $S D=0.82$ ). The interpretation of the model was the following: for each point that increased the Organizational Climate score, there was an increase of 0.486 points in the Work Satisfaction score, regardless of the other variables in the model. For the clinical nursing work area, there 
was an increase of 0.312 points in the Work Satisfaction score when compared to the other work areas. See table 3.

Regarding the dimensions of Organizational Climate, the results obtained through ECOOS showed that the global score for Organizational Climate had an average of 3.49 points (SD $=0.71$ points) and a median of 3.53 points, ranging from 1.63 to 5.00 points. As for dimensions, the highest scores were in Leadership (average of 3.81 points; $S D=0.99$ points), Relationship and Team Spirit (average of 3.73 points; $\mathrm{SD}=1.00$ points) and Safety at Work (average of 3.64 points; $S D=0.99$ points). The lowest score was in the Strategy (average of 2.83 points; $S D=0.98$ points). Remuneration averaged 3.55 points ( $S D=$ 0.96 points), Relationship with the Community averaged 3.41 points; $S D=0.85$ points), and Professional Development should average 3.15 points (SD $=1.00$ points).

The highlight for dimension 1 - Leadership, especially the items: my boss knows the technical aspects of his work well (4.55 points), communication with my boss is easy and open (4.20 points), I trust in the decisions made by my boss (4.02 points) and my boss accepts suggestions for improving the work (4.02 points). An important highlight for the items with the worst scores were there is equal treatment between managers and subordinates (3.27 points) and I participate in the decisions that affect my work (3.35 points).

The dimension of Hierarchical Relations pointed out weaknesses in equal treatment and a sense of justice with a low possibility of participating in decisions in the work area (both with an average of 3.12). Besides, low satisfaction with the support received from higher levels (average of 3.22), associated with low participation in decisions in the organization or in its work area (average 3.16).

\section{Discussion}

The average age coincides with the national scenario. It is worth noting that the study site has a percentage of workers over the age of 49 to 59.9 years. This has been occurring in the Brazilian scenario, since there is a need to maintain income, forcing the professional to continue working even after retirement. The reasons for this phenomenon are multifactorial, including criteria of a personal, cultural and economic nature ${ }^{12}$.

When observing the global score for Job Satisfaction (average of 3.22 points), it can be said that workers are satisfied with their work, an assessment strengthened by Intrinsic Job Satisfaction (average of 3.30; $S D=1.03$ ), with work being a great provider of Personal Achievement (average of 3.37) because workers have the possibility to do things they like (average of 3.37).

In the same sense, promoting the satisfaction of Hierarchical Relations (average 3.25 points; $S D=1.02$ points) also stood out. An average of 3.51 points was identified in the Work Supervision carried out by workers, in this hospital it is possible to maintain a good personal relationship with the authorities of power (average of 3.43), exercising a periodicity of supervision also with a high average (4.42 points). 
Sustained by the way in which they evaluate and judge the work of workers (average 3.38), which makes it possible to decide with autonomy on their own work (average 3.37).

This data is extremely relevant in the study, as it shows that the nursing team is satisfied with the supervision and with the good personal relationship established with the authorities. This is a positive response for leaders because it point out which paths they should continue to take in order to guarantee this satisfaction and even increase $i^{13}$.

The nursing exercise focuses on the interpersonal relationship of the nursing team, including the multidisciplinary team and the family. The patient whose values beliefs and desires of an individual or collective nature were been derived from the environment in which they live and have developed, therefore, must be considered to guarantee a positive organizational climate and consequently the satisfaction of professionals at work ${ }^{14}$.

When the organizational climate is positive, the tendency is for the satisfaction of personal and the professional has to be achieve. This was been represented by the relationships of satisfaction, collaboration, interest, motivations, among others that are evidenced by the workers. If the perception of the climate is negative, the environment becomes overloaded, tense, with the risk of frustrations of employees regarding their own needs, causing discontent and leading to disinterest, non-conformity, apathy and even diseases, such as the Burnout Syndrome.

In the Hierarchical Relations dimension, the items with the highest level of satisfaction were supervision with the work they do, personal relationships with the authorities, the periodicity of supervision, the way they evaluate and judge their work and the possibility of autonomously deciding on their own work. In this hospital, it is possible to maintain a good personal relationship with the authorities, exercising a periodicity of supervision sustained by the form in which they evaluate and judge the work of the workers, which makes it possible to decide with autonomy on their own work.

The Hierarchical Relationships also pointed out the lack of collaborators to participate in decisions in the work area. In addition to the insufficient support of the higher levels. In this aspect, it is possible to identify a similarity regarding the restrictions of power and autonomy, being these factors impeding the manifestation of a good relationship with colleagues, showing that dissatisfaction is more associated with the organizational culture itself, with greater or lesser participation. When investigating job satisfaction, identified "regular" satisfaction with Management Bodies, with lower rates for "management recognition" and "communication"15,16.

\section{Study Limitations}

Among the limitations of this study, we can mention the fact that it is a single hospital, being a specific sample and limited to civil servants in a Brazilian context. Thus, the results cannot be generalize to other types of organization. The fact that the study has a cross-sectional design prevented us from drawing 
conclusions about the temporal order of effects and causal relationships. To avoid such limitations, we suggest to the others the use of longitudinal methodologies within a multi-method approach.

A point to consider is that the assessment was been made with a focus on job satisfaction versus the organizational climate, not examining the quality of life that can intimately influence job satisfaction. It is interesting for future work to consider the multilevel relationships between attitudes, behaviors and aggregate performance at the team level.

\section{Conclusion}

The objective of this work was to investigate the association between job satisfaction and organizational climate of the nursing team workers in the context of a public hospital in Brazil. It was proved that there is a correlation between the Organizational Climate and Job Satisfaction, the higher the Organizational Climate score, the higher the Work Satisfaction score $(p<0.001, r=0.424)$. The organizational climate is something subjective. However, it represents the social atmosphere of an organization. This fact justifies the reason why it is fundamental to consider for achieving employee satisfaction at work.

The organizational climate is the expression of the feelings, perceptions and attitudes of the individual at work, which has influenced by human resource management practices, organizational values and interpersonal relationships in addition to policies that seek to establish goals and return for achieving them. Besides the internal contexts of health institutions, the worker as a complex being brings with him individual needs that, directly or indirectly, change his perception of satisfaction in the universe of work.

In the findings of this study, the highest level of job satisfaction has found in the Intrinsic Job Satisfaction dimension, which is been described as a feeling that work is conducive to personal fulfillment, as well as offering opportunities to do things in which the individual stands out and likes. The lowest level was the Physical Work Environment and this dimension has related to the physical structure, lighting, ventilation of the workplace as well as hygiene and health issues; this is justified by the sample being a university hospital (public). In Brazil, health resources are increasingly scarce. Consequently, the investment in infrastructure ends up been compromised. The proper maintenance of the infrastructure was been linked to the way in which the organizational structure and other administrative issues are handled in the institution where, sometimes, they are not simple practices.

Thus, it is possible to understand that the construct job satisfaction is an instant result of a complex context, in which the worker has inserted in his workplace. Being associated issues of the experiences of each of the individuals, including also the collective experiences, as well as the way these experiences were been interpreted by each of the members and by the institutions involved.

\section{Implications For Health Policy}

Understanding the relationship between organizational climate and job satisfaction provides subsidies for the elaboration of strategies to mitigate the processes of exhaustion, illness and incapacity of 
workers, as well as helping to improve the productivity and effectiveness of the nursing work process. It is also need to realize the correlated dimensions as fragile in order to maintain a positive organizational climate makes it possible to make a thorough analysis of the attitudes of nursing professionals on these aspects and seek to improve items that can affect the organizational climate and compromise job satisfaction.

The results suggest that the areas with the potential to initiate improvement strategies in search of job satisfaction are Satisfaction with Hierarchical Relations, Intrinsic Job Satisfaction, Leadership and Professional Development. Therefore, it is suggested for policy makers and administrators to emphasize policies that develop the leadership of professionals whose position positions themselves as managers, directors, coordinators, supervisors and that they improve their professional development techniques of the nursing team as a whole in search for full satisfaction of workers in the organization.

\section{Abbreviations}

Organizational Climate Scale for Health Organizations (ECOOS)

Work Satisfaction Questionnaire (S20 / S23)

Standard Deviation (SD)

\section{Declarations}

Ethics and consent to participate: This research project has approved by the Research Ethics Committee of the School of Nursing at the University of Sao Paulo, under opinion 912.483 of 11/17/2014 and formal authorization from the service that hosted the collection. The informed consent obtained from study participants was written, in accordance with the IRB rules.

Consent for publication: 'Not applicable' for that section.

Availability of data and material: Our datasets are available upon reasonable request. The correspondence author should be contacted if someone wants to request the data. This work is part of data from the master's thesis entitled Organizational Climate and Job Satisfaction in Nursing workers at a university hospital, related to the Graduate Program in Nursing Management (PPGEn), University of São Paulo School of Nursing.

Competing interests: The author(s) declared no potential conflicts of interest with respect to the research, authorship and/or publication of this article

Funding: This research received no specific grant from any funding agency in the public, commercial or not-for-profit sectors.

Authors' contributions: RY, PCPB designed the study. 
RY, VA collected the data.

RY, PCPB, CDAR analyzed the data.

PCPB supervised the study.

RY, VA, CDAR, PCPB involved in manuscript writing.

CDAR, PCPB involved in critical revisions for important intellectual content.

Acknowledgements: 'Not applicable' for that section.

\section{References}

1. Marx K. The capital. Critique of Political Economy. Book First. Sao Paulo: Nova Cultural, 1996 (in Portuguese).

2. Felli VEA., Baptista PCP. Nursing worker health. Sao Paulo: Manole. (in Portuguese), 2015.

3. Baptista PCP. Disability at work: the understanding of nursing managers [free teaching]. São Paulo: School of Nursing. Universidade de São Paulo (in Portuguese), 2014.

4. Pecino V, Díaz PA, Mañas MA. Clima, Estrés y Satisfacción Laboral: Un Estudio Multinivel en el SectorPúblico. Rev. Psicol. Soc., 2017; 32, 52-79.

5. Bakker AB., Demerouti E. Job Demands-Resources theory: Taking stock and looking forward. Journal of Occupational Health Psychology, 2017; 22, 273-285. https://doi.org/10.1037/ocp0000056

6. Pecino V. Organisational Climate, Role Stress, and Public Employees' Job Satisfaction. Int. J. Environ. Res. Public Health 2019, 16, 1792; doi:10.3390/ijerph16101792

7. Randhawa G, Kaur K. Organizational climate and its correlates: Review of literature and A proposed model. Journal of Management Research. 2014; 14(1): 25.

https://www.indianjournals.com/ijor.aspx?target=ijor:jmr\&volume=14\&issue=1\&article=003

8. Fleury MJ, et al. Associated and Mediating Variables Related to Job Satisfaction among Professionals from Mental Health Teams. Psychiatr Q; 2018; 89 (2):399-413. doi: 10.1007/s11126017-9543-6.

9. Nelson RE, Mei A. Production technology and organizational culture in a mass transportation company. Organization \& Society; 2017; 24 (81), 261-284. https://dx.doi.org/10.1590/19849230814 (in Portuguese).

10. Forehand GA, Gilmer HB. Environmental variation in studies of organizational behavior. Psychological Bulletin. 1964; 62 (6): 361-382. https://doi.org/10.1037/h0045960

11. Carlotto M, Câmara S. Psychometric properties of the Job Satisfaction Questionnaire (S20/23). Psico-USF; 2008; 13 (2):203-10 (in Portuguese). https://dx.doi.org/10.1590/S141382712008000200007 
12. Kaewpan W, Peltzer K. Nurses' intention to work after retirement, work ability and perceptions after retirement: a scoping review. The Pan African medical journal, 2019; 33, 217.

https://doi.org/10.11604/pamj.2019.33.217.17568

13. Díaz-Fúnez PA, et al. Role ambiguity, job satisfaction and organizational citizenship in the public sector: A multi-level mediation studio. Rev. Psycology. 2016; 34, 387-412 (in Spanish). https://dx.doi.org/10.18800/psico.201602.007

14. Japiassu,RB, Rached CDA. The leading nurse in coaching: review of the main scientific considerations. International Journal of Development Research, 2020; 10, 06, pp. 36782-36784 (in Portuguese). https://doi.org/10.37118/ijdr19042.06.2020

15. Silva CINP, da,Potra TMF dos S. Professional satisfaction of nurses in a local health unit: determinants of satisfaction. Nursing Journal Reference, 2019; IV (20), 117-128. https://dx.doi.org/10.12707/RIV18077 (in Portuguese).

16. Asgari $S$, et al. Relationship between moral distress and ethical climate with job satisfaction in nurses. Nurs Ethics. 2019; 26 (2), 346-356. doi: 10.1177/0969733017712083.

\section{Tables}


Table 1. Socio-demographic distribution of workers on the nursing team, Brazil, 2019.

\begin{tabular}{|c|c|c|c|c|c|c|c|}
\hline \multirow[t]{2}{*}{ Variable } & \multicolumn{2}{|c|}{ Participation* } & \multicolumn{2}{|c|}{ Losses } & \multicolumn{2}{|c|}{ Total } & \multirow[t]{2}{*}{$\mathrm{p} * *$} \\
\hline & $\mathbf{N}$ & $\%$ & $\mathbf{N}$ & $\%$ & $\mathbf{N}$ & $\%$ & \\
\hline \multicolumn{8}{|l|}{ Sexo } \\
\hline Female & 200 & 88.5 & 245 & 87.5 & 445 & 87.9 & 0.732 \\
\hline Male & 26 & 11.5 & 35 & 12.5 & 61 & 12.1 & \\
\hline \multicolumn{8}{|c|}{ Age group (years) } \\
\hline Less than 40.0 & 62 & 27.4 & 41 & 14.6 & 103 & 20.4 & 0.002 \\
\hline 40.0 to 49.9 & 64 & 28.3 & 98 & 35.0 & 162 & 32.0 & \\
\hline 50.0 to 59.9 & 82 & 36.3 & 105 & 37.5 & 187 & 37.0 & \\
\hline 60.0 and more & 18 & 8.0 & 35 & 12.5 & 53 & 10.5 & \\
\hline Uninformed & 0 & 0.0 & 1 & 0.4 & 1 & 0.2 & \\
\hline \multicolumn{8}{|c|}{ Professional qualification } \\
\hline Nursing assistant & 16 & 7.1 & 43 & 15.4 & 59 & 11.7 & 0.015 \\
\hline Nursing Technician & 123 & 54.4 & 149 & 53.2 & 272 & 53.8 & \\
\hline Nurse & 85 & 37.6 & 90 & 32.1 & 175 & 34.6 & \\
\hline Uninformed & 2 & 0.9 & -2 & -0.7 & 0 & 0.0 & \\
\hline \multicolumn{8}{|c|}{ Length of experience at the Hospital (years) } \\
\hline Less than 11.0 & 58 & 25.7 & 34 & 12.1 & 92 & 18.2 & $<0,001$ \\
\hline 11.0 to 20.9 & 79 & 35.0 & 102 & 36.4 & 181 & 35.8 & \\
\hline 21.0 and more & 82 & 36.3 & 151 & 53.9 & 233 & 46.0 & \\
\hline Uninformed & 7 & 3.1 & -7 & -2.5 & 0 & 0.0 & \\
\hline \multicolumn{8}{|l|}{ Workspace } \\
\hline Clinical Nursing & 40 & 17.7 & 60 & 21.4 & 100 & 19.8 & 0,002 \\
\hline Surgical Nursing & 52 & 23.0 & 44 & 15.7 & 96 & 19.0 & \\
\hline Obstetric Nursing & 31 & 13.7 & 67 & 23.9 & 98 & 19.4 & \\
\hline Pediatric Nursing & 50 & 22.1 & 44 & 15.7 & 94 & 18.6 & \\
\hline Outpatients & 36 & 15.9 & 66 & 23.6 & 102 & 20.2 & \\
\hline Management & 4 & 1.8 & 12 & 4.3 & 16 & 3.2 & \\
\hline
\end{tabular}




\begin{tabular}{lrrrrrrr} 
Uninformed & 13 & 5.8 & -13 & -4.6 & 0 & 0.0 \\
\hline & Total & 226 & 100.0 & 280 & 100.0 & 506 & 100.0 \\
\hline
\end{tabular}

Note: uninformed and negative values are due to inconsistencies in the databases and were not considered in the calculations of the chi-square test

Source: own study

Table 2. Descriptive statistics of the dimensions * of job satisfaction, nursing workers, Brazil, 2019.

Dimension

N Average Median Standard Minimum Maxim

deviation

\begin{tabular}{lcccccc}
\hline 1. Satisfaction with Hierarchical Relations & 235 & 3.5 & 3.27 & 1.02 & 1.00 & 5.00 \\
\hline $\begin{array}{l}\text { 2. Satisfaction with the Physical Work } \\
\text { Environment }\end{array}$ & 235 & 3.13 & 3.20 & 1.08 & 1.00 & 5.00 \\
\hline 3. Intrinsic Job Satisfaction & 232 & 3.30 & 3.50 & 1.03 & 1.00 & 5.00 \\
\hline Global Job Satisfaction Score & 227 & 3.22 & 3.30 & 0.89 & 1.20 & 5.00 \\
\hline
\end{tabular}

* Scores ranging from 1.00 to 5.00 points

Source: own study 
Table 3. Factors associated with the Job Satisfaction score identified through linear regression analysis, Nursing workers, Brazil, 2019.

\begin{tabular}{|c|c|c|c|c|c|c|c|c|}
\hline \multirow[t]{2}{*}{ Variables } & \multicolumn{4}{|c|}{ Bivariate } & \multicolumn{4}{|c|}{ Multiple } \\
\hline & $\beta$ & $\mathrm{IC}_{95 \%}(\beta)$ & $\mathbf{p}$ & $\mathbf{r}^{2}$ & $\beta$ & $\mathrm{IC}_{95 \%}(\beta)$ & $\mathbf{p}$ & $r^{2} a$ \\
\hline \multirow[t]{2}{*}{ Organizational climate } & 0.525 & {$[0.340$} & $<0.001$ & 0.18 & 0.486 & {$[0.326 ;$} & $<0.001$ & 0.21 \\
\hline & & $0.697]$ & & & & $0.646]$ & & \\
\hline \multirow[t]{2}{*}{ Age (in years) } & 0.011 & {$[-0.001$} & 0.061 & 0.02 & -- & -- & -- & \\
\hline & & $0.023]$ & & & & & & \\
\hline Workspace * & & & & 0.06 & & & & \\
\hline \multirow[t]{2}{*}{ Clinical Nursing } & 0.320 & {$[0.020$} & 0.037 & & 0.312 & {$[0.018$} & 0.038 & \\
\hline & & $0.620]$ & & & & $0.606]$ & & \\
\hline \multirow[t]{2}{*}{ Pediatric Nursing } & -0.347 & {$[-0.637$} & 0.019 & & -0.308 & {$[-0.595$} & 0.036 & \\
\hline & & $-0.057]$ & & & & $-0.020]$ & & \\
\hline \multirow[t]{2}{*}{ Time of training in the profession (in years) } & 0.008 & {$[0.005$} & 0.224 & 0.01 & -- & -- & -- & \\
\hline & & $0.020]$ & & & & & & \\
\hline Liability for people who are dependent on & 0.262 & {$[-0.012$} & 0.061 & 0.02 & -- & -- & -- & \\
\hline care: not informed or not informed & & $0.536]$ & & & & & & \\
\hline \multirow[t]{2}{*}{ Male ** } & -0.180 & {$[-0.564$} & 0.357 & 0.00 & -0.180 & {$[-0.549$} & 0.340 & \\
\hline & & $0.204]$ & & & & $0.190]$ & & \\
\hline
\end{tabular}

* Reference category: other work areas

** Reference category: female

Source: own study

\section{Supplementary Files}

This is a list of supplementary files associated with this preprint. Click to download.

- Data.xlsx 